\title{
Influence of Laser Power and Powder Feed Rate on the Microstructure Evolution of Laser Metal Deposited Ti-5553 on Forged Substrates

\author{
C. Hicks ${ }^{\mathrm{a},{ }^{*}}$, T. Konkova ${ }^{\mathrm{a}, \mathrm{b}}$, P. Blackwell ${ }^{\mathrm{a}, \mathrm{b}}$
}

aDesign, Manufacturing \& Engineering Management (DMEM) Department, University of Strathclyde, 75

Montrose Street, Glasgow, UK

${ }^{\mathrm{b}}$ Advanced Forming Research Centre (AFRC), University of Strathclyde, 85 Inchinnan Drive, Glasgow, UK

*Corresponding author.

E-mail address: calum.hicks@strath.ac.uk

\begin{abstract}
In this work, titanium blocks of Ti-5Al-5Mo-5V-3Cr (Ti-5553) have been Laser Metal Deposited (LMD) on forged substrate of the same alloy under varying laser power and powder feed rates. The microstructure has been characterized using optical microscopy, scanning electron microscopy and Electron backscatter diffraction (EBSD) techniques. Microstructure was predominantly large columnar $\beta$-grains aligned with the build direction interspersed with fine equiaxed $\beta$-grains. Increase in the powder feed rate was found to reduce the average $\beta$-grain size and promoted clusters of fine grains to be retained during the deposition of subsequent layers. Increase in the laser power also reduced the average $\beta$ grain size and promoted greater nano-scaled $\alpha$ precipitates at the substrate interface and initial deposited layers which significantly increased the microhardness in this area. Dendrites exist due to micro-segregation of solutes during rapid solidification which create preferential regions for $\alpha$ nucleation. A difference in texture was observed between specimens manufactured with varying laser powers: a low laser power produced a cube texture and a higher laser power produced a $<001>/ /$ BD fibre texture.
\end{abstract}

Keywords:

Laser Metal Deposition

$\beta$-Titanium Alloy

Microstructure

Microhardness

Texture

Electron backscatter diffraction (EBSD)

\section{Introduction}

Additive manufacturing (AM) is an emerging technology that has the potential to reduce the manufacturing costs associated with machining large titanium forgings [1]. Moreover, AM can add details to pre-existing components and repair surface defects [1-3]. Laser Metal Deposition (LMD) is one AM technology that uses a high-powered laser to create a melt-pool on a substrate material. Metallic powder is simultaneously coaxially blown into the melt-pool with an inert gas, typically Argon. The laser follows a pre-determined path created with CAD software. Once each layer has solidified, the process can be repeated to deposit material that satisfies the desired geometry. The process produces near-net shape components and is therefore particularly attractive for use with expensive titanium alloys such as Ti-5Al-5Mo-5V-3Cr (Ti-5553) which is used in high strength aerospace undercarriage applications. Specifically, there is interest in the potential to deposit small details, such as lugs or spigots, using LMD to larger forgings [4].

As with all AM processes, the widespread adoption of LMD faces several challenges. Firstly, LMD components are typically prone to porosity which radically affects the mechanical properties [5-7]. Secondly, large peak residual stresses are often observed within the deposited layers and the substrate [8-10]. Lastly, LMD components often display unique anisotropic microstructures due to the rapid and directional heating and cooling cycles $[9,11-$ $13]$.

Significant effort is being applied to the optimisation of the deposited layers, especially with regard to the effects of the process parameters of LMD such as laser power or powder feed rate. The bulk of research attention has been on the widely used $\alpha+\beta$ alloy, Ti-6Al-4V. Comparably, less attention has been applied to the $\beta$-Ti alloys, such as Ti-5553 and there is still significant scope for optimising the LMD as-deposited properties. On quenching 
from high temperatures, $\beta$-Ti alloys solidify into $\beta$ phase and typically undergo subsequent ageing heat treatment to precipitate the $\alpha$ phase as fine laths which significantly strengthen the alloy [14]. Moreover, unlike Ti-6Al-4V which has a low growth restriction factor (Q) of 1.6 [15], the Ti-5553 alloy has a significantly higher Q value of an estimated 38.9 [16]. This is expected to promote a constitutionally supercooled region ahead of the solid/liquid interface, forming dendritic growths and the possibility of equiaxed grain nucleation [15].

Hatefi and Attalah investigated the effect of laser power, laser scanning velocity and powder feed rate on the build height of LMD Ti-5553 [4]. They noted that only subsequent solution treatment and ageing could produce the desired tensile strength of the deposited components. However, post-heat treatments may be undesirable as this may compromise the mechanical properties of the substrate. Similar work by Qiu et al. attempted to apply in-situ annealing and dwelling passes to raise the as-deposited mechanical strength [17]. They noted that both techniques produced significantly greater nano-scaled $\alpha$ precipitates within the initial layers of the build, which correspondingly increased the micro-hardness of this area. Despite the above efforts, greater understanding of the microstructure evolution during LMD of Ti-5553 is required to optimise as-deposited components. In this work the laser power and powder feed rate have been varied to better understand their effect on the as-deposited microstructure development through the deposited layers.

\section{Experimental}

Ti-5553 was used as workpiece material in this research. A forged Ti-5553 billet with composition outlined in Table 1 was preliminarily subjected to $\beta$ annealing at $960^{\circ} \mathrm{C}$ for 3 hours in a vacuum furnace and followed by air cooling at $10^{\circ} \mathrm{C}$ per minute to room temperature. In addition, an ageing treatment was conducted at $810^{\circ} \mathrm{C}$ for 2 hours followed by a water quench. The substrate material was extracted from the forged billet. The powder feedstock was atomised using a plasma atomisation process and subsequently sieved into a particle size distribution of 45-106 $\mu \mathrm{m}$. The powder chemical composition is outlined in Table 1. A sample of the powder was mounted and cross-sectioned using normal grinding and polishing methods for EBSD analysis.

Table 1 - Nominal chemical composition of the Ti-5553 billet and plasma atomised Ti-5553 powder as provided by manufacturers.

\begin{tabular}{|c|c|c|c|c|c|c|c|c|c|c|}
\hline $\mathrm{Wt}, \%$ & $\mathrm{Ti}$ & $\mathrm{Al}$ & Mo & $\mathrm{V}$ & $\mathrm{Cr}$ & $\mathrm{Fe}$ & $\mathrm{O}$ & $\mathrm{N}$ & $\mathrm{C}$ & $\mathrm{H}$ \\
\hline Substra & Balance & 5.28 & 5.34 & 4.85 & 2.73 & 0.37 & - & - & - & - \\
\hline Powder & Balance & 5.07 & 4.92 & 5.01 & 2.92 & 0.35 & 0.057 & 0.009 & 0.008 & 0.002 \\
\hline
\end{tabular}

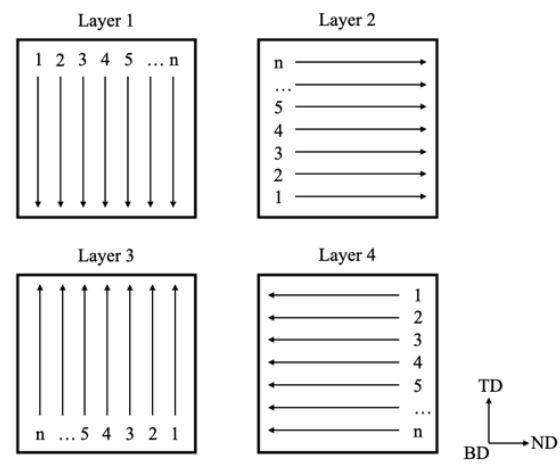

Figure 1 - LMD Scanning pattern.

Blocks of Ti-5553 were deposited on the Ti-5553 substrate by LMD with a $2 \mathrm{~kW}$ TRUMPF disk laser. Each block was of dimensions $15 \times 15 \mathrm{~mm}^{2}$ in the normal and transverse directions (ND and TD respectively) and consisted of 16 layers incrementally spaced by $0.4 \mathrm{~mm}$ through the build direction (BD). The spacing between scan track centrelines within each layer was $0.8 \mathrm{~mm}$. The scanning pattern was linear tracks aligned in the same direction, upon which each layer rotates the pattern by 90 degrees as illustrated in Figure 1. Localised argon shielding was used. The scanning speed was $600 \mathrm{~mm} / \mathrm{min}$. Five blocks were assessed for microstructural examination and their associated process parameters are outlined in Table 2. In addition, a single layer deposited with LP/HF process parameters (see Table 2) was deposited to investigate microstructure evolution. 
Table 2 - LMD deposited specimen nomenclature and associated process parameters.

\begin{tabular}{ccc}
\hline Specimen & Laser Power, W & Powder-feed rate, g/min \\
\hline LP/LF (low power/low feed rate) & 550 & 1.4 \\
LP/MF (low power/medium feed rate) & 550 & 1.8 \\
LP/HF (low power/high feed rate) & 550 & 2.3 \\
HP/LF (high power/low feed rate) & 650 & 1.4 \\
HP/MF (high power/medium feed rate) & 650 & 1.8 \\
\hline
\end{tabular}

Blocks were sectioned parallel to the build direction, i.e. in the BD-ND plane, through the centre of the build as diagrammatically shown in Figure 2. Standard techniques of metallographic preparation were applied, i.e. grinding and polishing followed by etching with Kroll's reagent for optical microscopy (OM). For scanning electron microscopy (SEM), the samples were subjected to electro-polishing in an electrolyte consisting of methanol, 2-butoxyethanol and perchloric acid at $40 \mathrm{~V}$ for 30 seconds followed by washing with methanol and drying with an air flow. SEM imaging and electron back-scatter diffraction (EBSD) analysis was obtained using a Thermo Fisher Scientific Quanta 250 SEM and an Oxford Instrument EBSD camera, with a $20 \mathrm{kV}$ accelerating voltage and a $4.5 \mu \mathrm{m}$ spot size. EBSD maps were created with a $5 \mu \mathrm{m}$ step size and achieved a minimum indexed proportion of $80 \%$ for all scans. Micro-chemical analysis was carried out with an Oxford Instruments X-Max 50 $\mathrm{mm}^{2}$ energy dispersive X-ray (EDX) spectrometer with an accelerating voltage of $15 \mathrm{kV}$ and spot size of $5.2 \mu \mathrm{m}$.

EBSD post-processing and analysis was completed in AZtecHKL software by Oxford Instruments. Noise reduction has been applied to replace non-indexed pixels with orientations based on neighbouring pixels. A misorientation threshold of 15 degrees was applied to differentiate low-angle boundaries (LABs) from high-angle boundaries (HABs). Grains were characterised as areas surrounded by a HAB perimeter. Grain size measurements were conducted by line intercept method in both BD and ND axis using grain reconstruction in the AZtecHKL software.
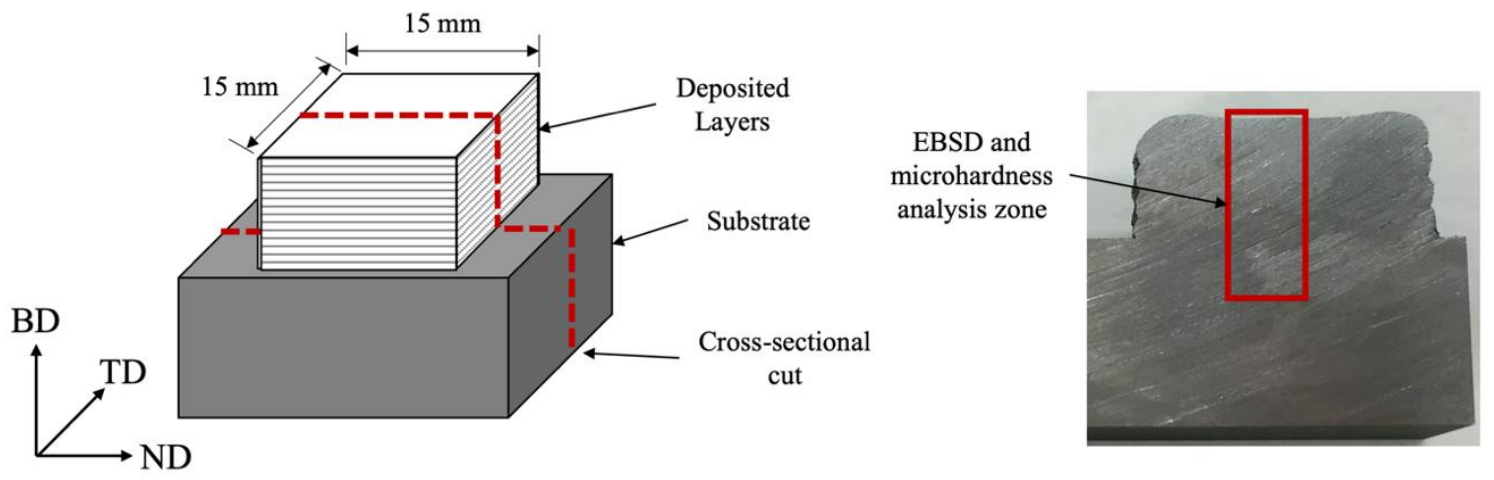

Figure 2 - Specimen geometry overview (left), and EBSD and microhardness analysis area of cross-sectioned material (right).

Vickers microhardness distribution testing was conducted on a DuraScan 70 G5 hardness tester for a load of $1 \mathrm{~kg}$ (HV1) for $10 \mathrm{~s}$. The spacing between indents was $0.75 \mathrm{~mm}$. Three parallel lines of hardness distributions through the build direction, spaced $6,6.75$, and $7.5 \mathrm{~mm}$ from the specimen edge were taken and averaged for each specimen.

\section{Results and Discussion}

The build height of each specimen is outlined in Table 3. Based on a predicted build height of 6.4 mm (16 layers incrementally spaced by $0.4 \mathrm{~mm}$ ), it is noted that specimen LP/MF and HP/LF are close to the predicted build height, whilst specimen LP/LF is underbuilt (the build height was less than the predicted height) and specimens $\mathrm{LP} / \mathrm{HF}$ and HP/MF are overbuilt (the build height was greater than the predicted height). It is thought that not all the powder is typically 'captured' by the melt-pool. Therefore, taking specimen LP/LF as an example, increasing the melt-pool size to capture more powder, or increasing the concentration of powder entering the melt-pool will increase the build height; either of which can be achieved by increasing the laser power or powder feed rate. A minimal build height per layer is required to avoid the laser beam (which moves in incremental steps per layer of $0.4 \mathrm{~mm}$ ) losing focus as the build progresses. In the case of specimen LP/LF this may have played a role in the low build height. 
Table 3 - Deposited specimen build heights.

\begin{tabular}{llllll}
\hline Specimen & LP/LF & LP/MF & LP/HF & HP/LF & HP/MF \\
\hline Build height, $\mathrm{mm}$ & 4.59 & 6.58 & 7.41 & 6.45 & 7.66 \\
\hline
\end{tabular}

\subsection{Macrostructure}

Figure 3 shows OM micrographs of specimen in the etched condition. In these images, several microstructural features can be observed, including columnar $\beta$-grains aligned with BD in the deposited material, and large equiaxed $\beta$-grains in the substrate, the fusion zone (FZ), and the heat affected zone (HAZ). In general, the FZ substrate penetration is $\approx 300 \mu \mathrm{m}$ and the HAZ penetration is $\approx 1000 \mu \mathrm{m}$. The microstructure of the deposited material is characterised by the presence of layer bands and dendrites as visible in Figure 3c. Layer bands have been observed in Ti-alloy LMD deposits and welds [11,18-20], but few authors have investigated their formation or reached an agreed conclusion. Liu et al. noted the layer bands are regions of locally different composition compared to the bulk material and contains a greater extent of homogenisation [11]. Zhu et al. theorised the layer band formation is due to a superheating effect on the previously deposited layer from the melt-pool, creating a narrow band with a peak temperature higher than the solidus temperature, but remaining in the solid-phase perhaps due to insufficient holding time. The superheating effect promoting a higher diffusivity of elements and therefore greater homogenisation within the layer band [20]. Dendritic growths extend out perpendicularly to the layer bands. In specimens in this work, the layer bands are incrementally spaced at approximately $400 \mu \mathrm{m}$ throughout the $\mathrm{BD}$, corresponding to the layer thickness process parameter. The final layer bands are approximately $700 \mu \mathrm{m}$ from the top surface, indicating that significant re-melting occurs during the deposition of each layer.
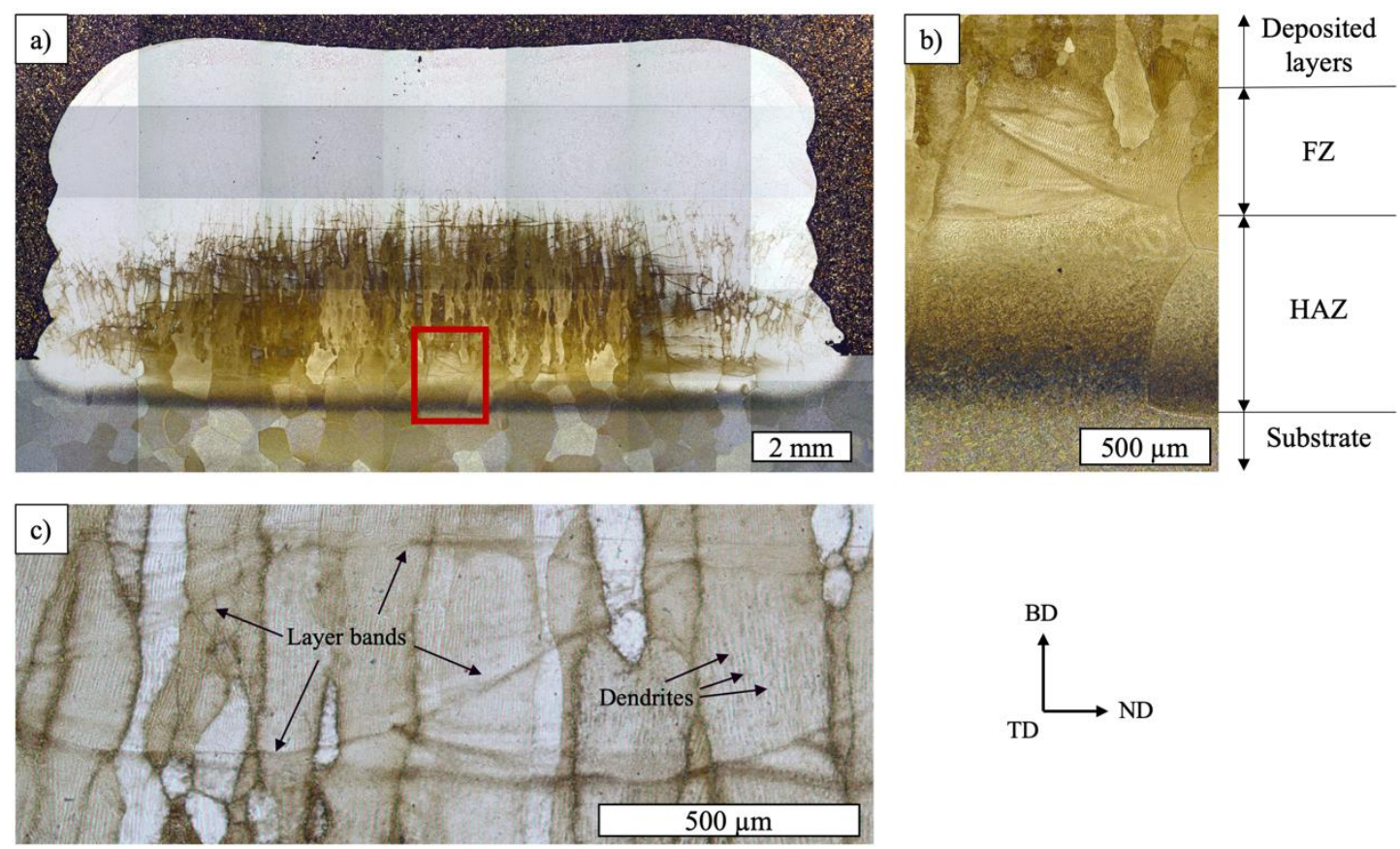

Figure 3 - Microstructure of specimen HP/LF: (a) overview, and (b) magnification of area outlined in (a). (c) detail of deposited layers in specimen LP/MF.

Figure 4 shows the orientation image maps (OIM) for each specimen with inverse pole figure (IPF) colour contrast with respect to the BD axis. Areas have been discretised (as shown by the dashed black lines) to indicate areas used for grain size analysis. Based on these areas, $\beta$ grain sizes and aspect ratios have been calculated and are outlined in Table 4. The overall dominant grain orientation in each specimen is $<001\rangle / / \mathrm{BD}$ (as indicated by the majority of red coloured grains). Fine equiaxed grains of $<120 \mu \mathrm{m}$ can be seen lining the top of the build towards the sample surface and dispersed throughout the build. Such grains can be seen distributed along bands parallel to ND in specimens LP/MF, LP/HF and HP/MF as indicated by the arrows in Figure 4. The area fraction of these grains is detailed in Table 4. The distribution of $\beta$ grain sizes of each specimen along BD is shown in Figure 5 as measured by the line intercept method. A large peak in the area of grains with an average size of $<100 \mu \mathrm{m}$, as well as the presence of grains $>1 \mathrm{~mm}$ was observed. Specimen LP/LF was characterized by the presence of several large grains, with the largest $>3 \mathrm{~mm}$. Increasing the laser power resulted in a decrease in the average $\beta$ grain size. Similarly, an increase in the powder feed rate for a given laser power resulted in a reduction in the average $\beta$ grain 
size (Table 4). A similar outcome was observed in LMD of the $\alpha+\beta$ alloy, TC11, by Wang et al. [21], who demonstrated that increasing the mass feed rate increases the number of fine equiaxed grains, whilst a reduction results in a microstructure dominated by larger columnar grains. It was thought that the increased powder feed rate increases the number of possible nuclei for new grains by flooding the melt-pool with more powder particles. This is reflected in the specimens in this work by an increase in the area fraction of small grains with increasing powder feed rate.

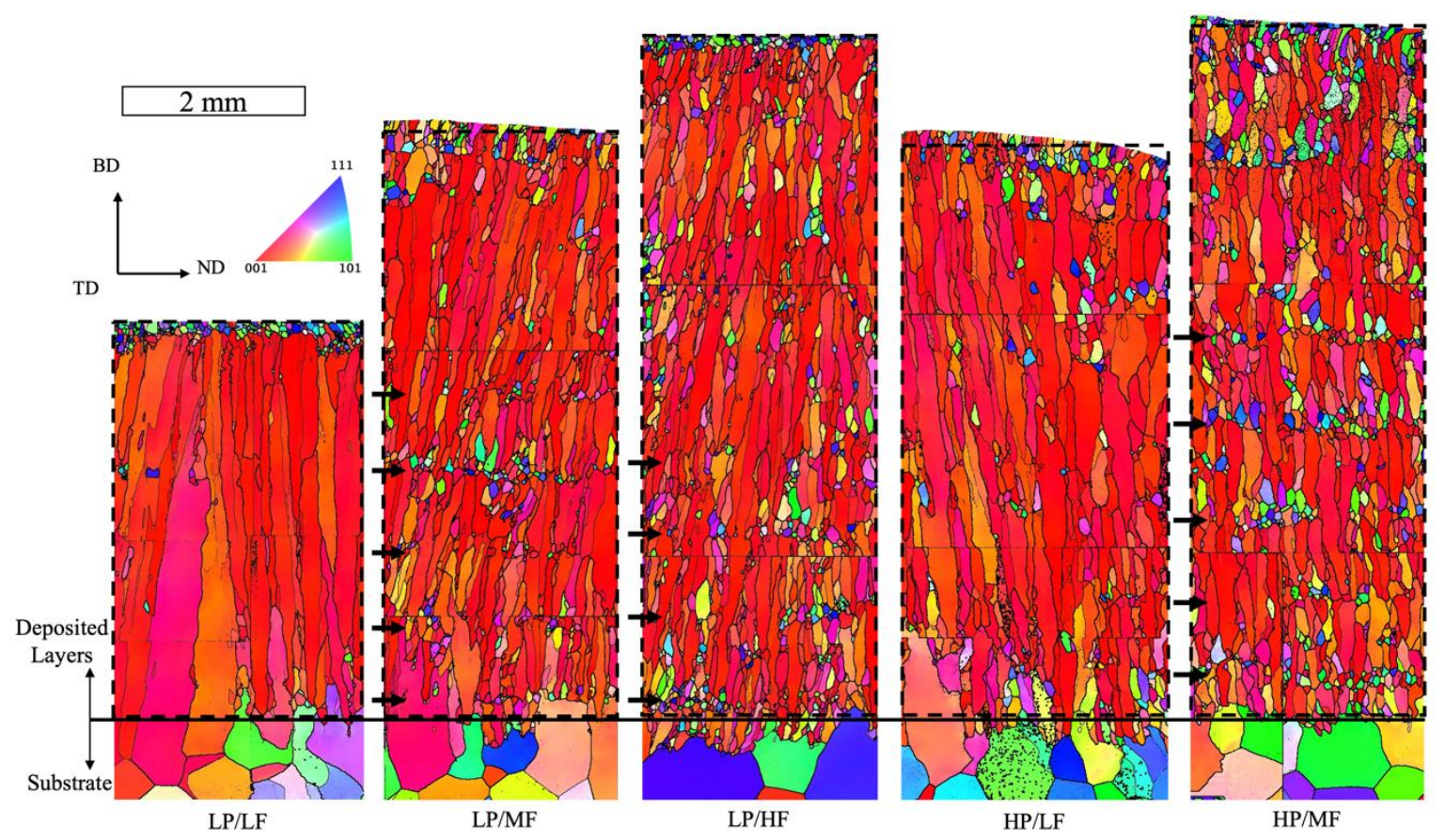

Figure 4-OIM IPF maps of specimen's cross-section.

Table 4 - Average $\beta$ grain sizes of deposited layers.

\begin{tabular}{llllll}
\hline & LP/LF & LP/MF & LP/HF & HP/LF & HP/MF \\
\cline { 2 - 6 } $\begin{array}{l}\text { Average } \beta \text { grain } \\
\text { size along BD, } \mu \mathrm{m}\end{array}$ & 322 & 206 & 140 & 195 & 156 \\
$\begin{array}{l}\text { Average } \beta \text { grain } \\
\text { aspect ratio }\end{array}$ & 2.1 & 2.5 & 1.7 & 1.9 & 1.8 \\
$\begin{array}{l}\text { Area fraction of } \\
\text { grains }<120 \mu \mathrm{m}\end{array}$ & $3.4 \%$ & $8.9 \%$ & $12.5 \%$ & $6.1 \%$ & $12.2 \%$ \\
\hline
\end{tabular}

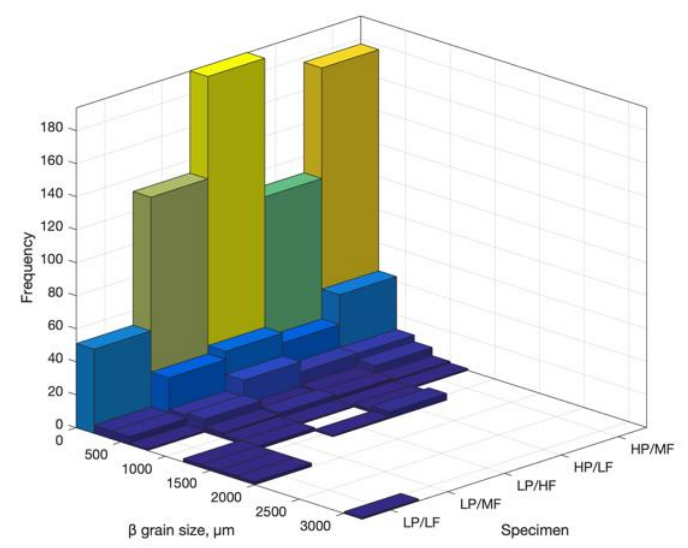

Figure 5 - $\beta$ grain size histograms as measured by line intercept method along BD axis. 


\subsection{Microstructure and Texture Evolution}

Detail of the microstructure within an individual $90 \mu \mathrm{m}$ diameter powder particle is shown in Figure 6a, which shows fine equiaxed $\beta$ grains between 2 to $45 \mu \mathrm{m}$. Figure $6 \mathrm{~b}$ shows an OIM of an individual layer deposited with the same process parameters as specimen LP/HF. Layer bands have been overlaid to better understand the microstructure formation. A region of fine equiaxed $\beta$ grains with an average size of $38 \mu \mathrm{m}$ can be seen lining the top of the deposited bead. Immediately below this exists a region of columnar $\beta$ grains followed by the large equiaxed $\beta$ grains of the substrate. Detail of the microstructure of specimen LP/HF with overlaid layer bands is shown in Figure 6c, which shows columnar grains spread through layer bands; and fine equiaxed grains distributed along tracks parallel to ND and in clusters in tracks parallel to TD as indicated by the white arrows in Figure 6c.
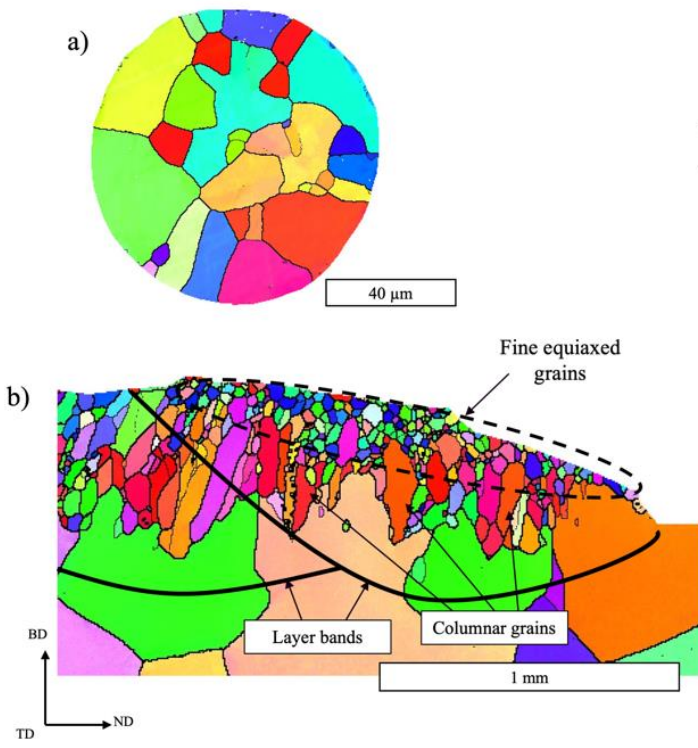
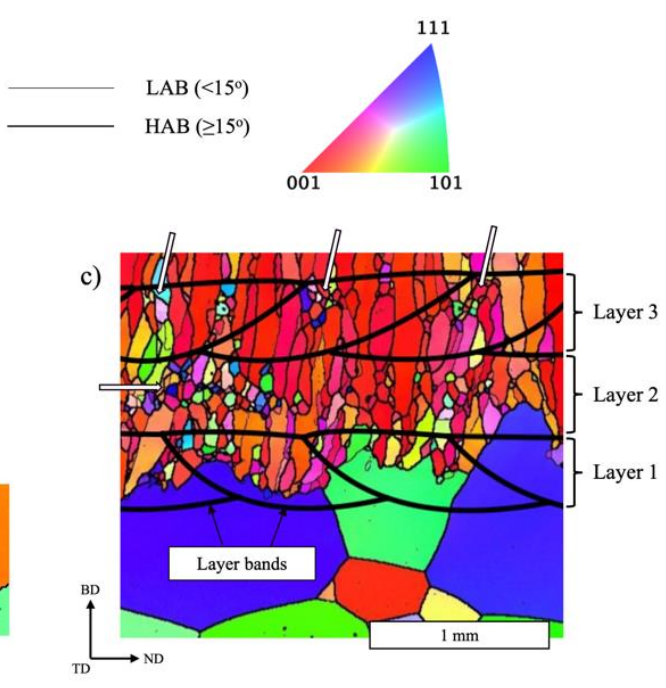

Figure 6 - OIM maps of: (a) an individual powder particle, (b) a single deposited layer with LP/HF process parameters, and (c) the initial deposited layers of specimen LP/HF.

The regions of small equiaxed grains and large columnar grains within the first deposited layer (Figure 6b) are indicative of different solidification mechanisms. Epitaxial growth is common in LMD produced titanium microstructures; creating columnar grains that grow through many layers, often reaching several millimetres in length [11,17,19,21-24]. Columnar grains were observed in all analysed specimens highlighting the presence of epitaxial growth phenomenon. The region of smaller equiaxed grains adjacent to the top surface has been noted by several authors to be caused by incomplete melted powder serving as heterogeneous nuclei $[15,19,21,24]$. Work by Zhu et al. [15] has shown this columnar to equiaxed transition in LMD Ti-alloys to require both a sufficient constitutionally supercooled region ahead of the solid/liquid interface and nucleation possibilities within the supercooled region from incomplete melted powder particles. Developing greater residual heat in the build by operating at higher laser powers, or a cooler melt-pool caused by an increase in powder feed rate, will reduce thermal gradients within the melt-pool, and is therefore expected to promote greater constitutional supercooling [25], and create more favourable conditions for nucleation of equiaxed grains on incomplete melted powder particles. The grain morphology of the individual powder particle imaged in Figure 6a, consists of a similar morphology to that of the region of fine equiaxed grains of the individual layer. Moreover, increasing the powder feed rate or laser power promotes a greater area fraction of these fine equiaxed regions within deposited material: fostering confidence in the theory of incomplete melted powder serving as heterogeneous nuclei within the constitutionally supercooled region.

The pole figure of the fine equiaxed grains detailed in Figure $6 \mathrm{~b}$ is shown in Figure $7 \mathrm{a}$. It can be seen that the texture is a weak <001> // BD fibre that is offset into the negative TD and positive ND direction. During directional solidification, it is easier for atoms within the liquid melt to adhere to less closely packed planes; for cubic crystal structures, such as the body centred cubic (BCC) $\beta$ phase, this corresponds to the $\{100\}$ planes [26]. BCC grains with their $\{100\}$ plane closer oriented to the direction of maximum thermal gradient will solidify faster and 'outgrow' less preferentially oriented grains. It is well understood that the moving melt-pool during LMD creates a trailing melt-pool with a curved melt-pool surface [23], as shown in Figure 7b and c. The direction of largest thermal gradient is perpendicular to the melt-pool curved surface and defines the preferential direction 
for the growth of $\{100\} \beta$ grain direction. In this case, the direction of maximum thermal gradient would be expected to be tilted away from the BD axis and into the laser travel direction (negative TD) and direction of track succession (positive ND). This phenomenon reflects the tilt in the fibre texture from the single deposited layer seen in Figure $7 \mathrm{a}$.

a)

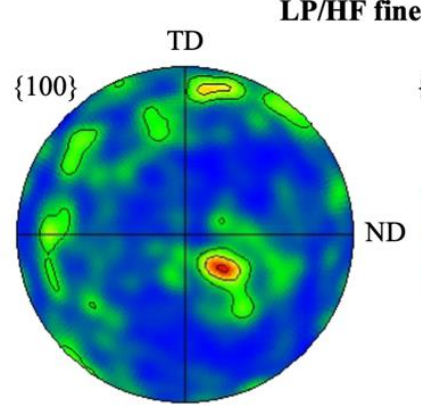

LP/HF fine equiaxed grains and associated hatch pattern

b)
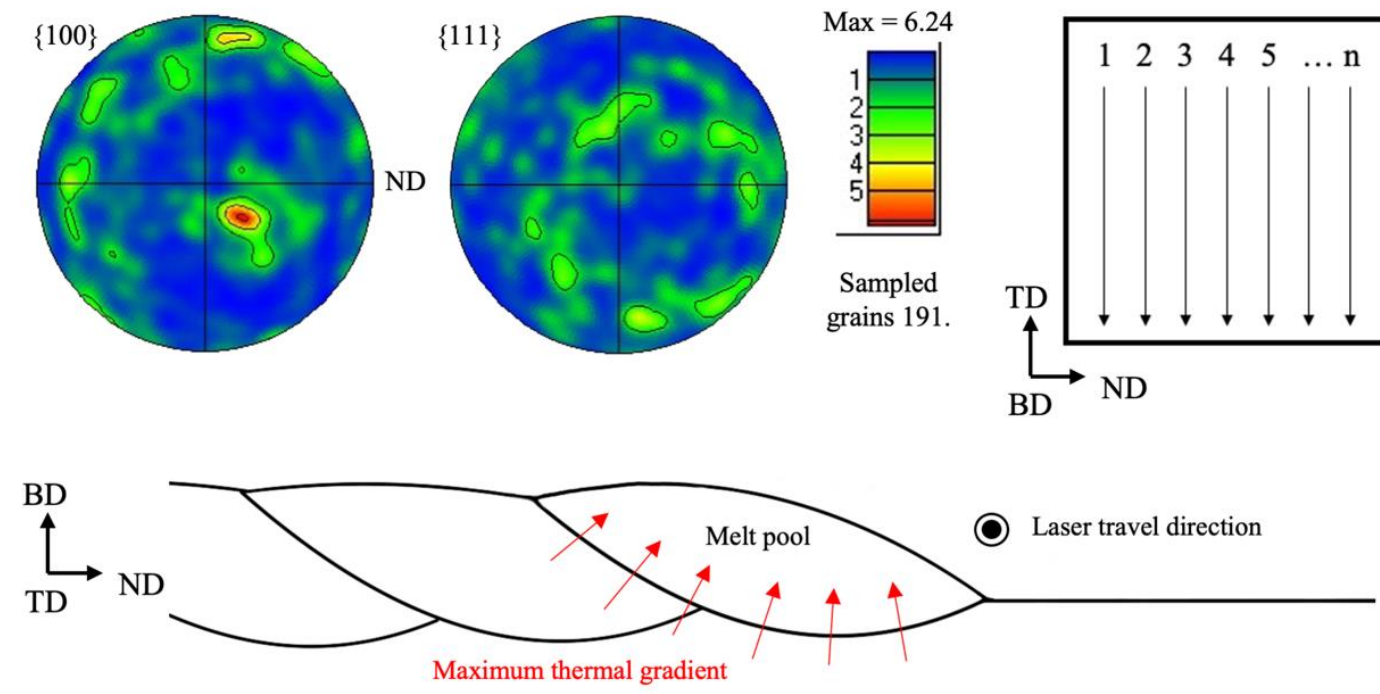

c)

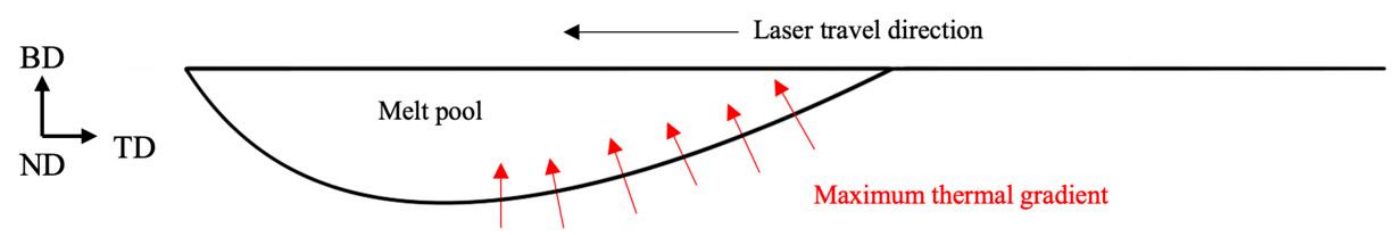

Figure 7 - (a) Pole figure and associated hatch pattern of the fine equiaxed grains from a single deposited layer of specimen LP/HF as outlined in Figure 6b. (b-c) schematic drawings of the direction of maximum thermal gradient with respect to the melt-pool geometry.

To investigate the texture evolution during the deposition of multiple layers, Figure 8 shows the $\{100\}_{\beta}$ pole figures and the corresponding hatch pattern for the first five layers of specimen $\mathrm{LP} / \mathrm{HF}$ and the fine equiaxed grains adjacent to the top surface in the final layer of the specimen. Also included is the predicted direction of maximum thermal gradient within each layer. In the case of the first layer (Figure 8a), there is a tilt in the fibre in the direction of maximum thermal gradient, much like that of the single layer previously discussed. In layer 2 (Figure 8b), no significant change in tilt can be observed even though the hatch pattern, and therefore direction of maximum thermal gradient, has changed anti-clockwise 90 degrees around the BD axis. In the remaining pole figures for layers 3-5 (Figure $8 \mathrm{c}-\mathrm{e}$ ), there is a marginal tilt in the $\langle 100\rangle$ fibre texture from alignment with the BD axis into the direction of the maximum thermal gradient of the previous layer. This phenomenon is explained by the fact that the majority of grains within any given layer are epitaxially grown from grains of the previous layer. Only new grains nucleated within the layer will grow with a tilted fibre texture along the line of maximum thermal gradient of the new layer. The final layers within each specimen contain a comparatively greater proportion of heterogeneously nucleated grains, because of the lack of re-melting which occurs during the deposition of subsequent layers and should therefore display a tilted fibre texture into the direction of maximum thermal gradient. This is confirmed in the pole figure of the heterogeneous grains in the final layer of specimen LP/HF as shown in Figure 8f which displays a tilted fibre texture corresponding to the direction of maximum thermal gradient. 


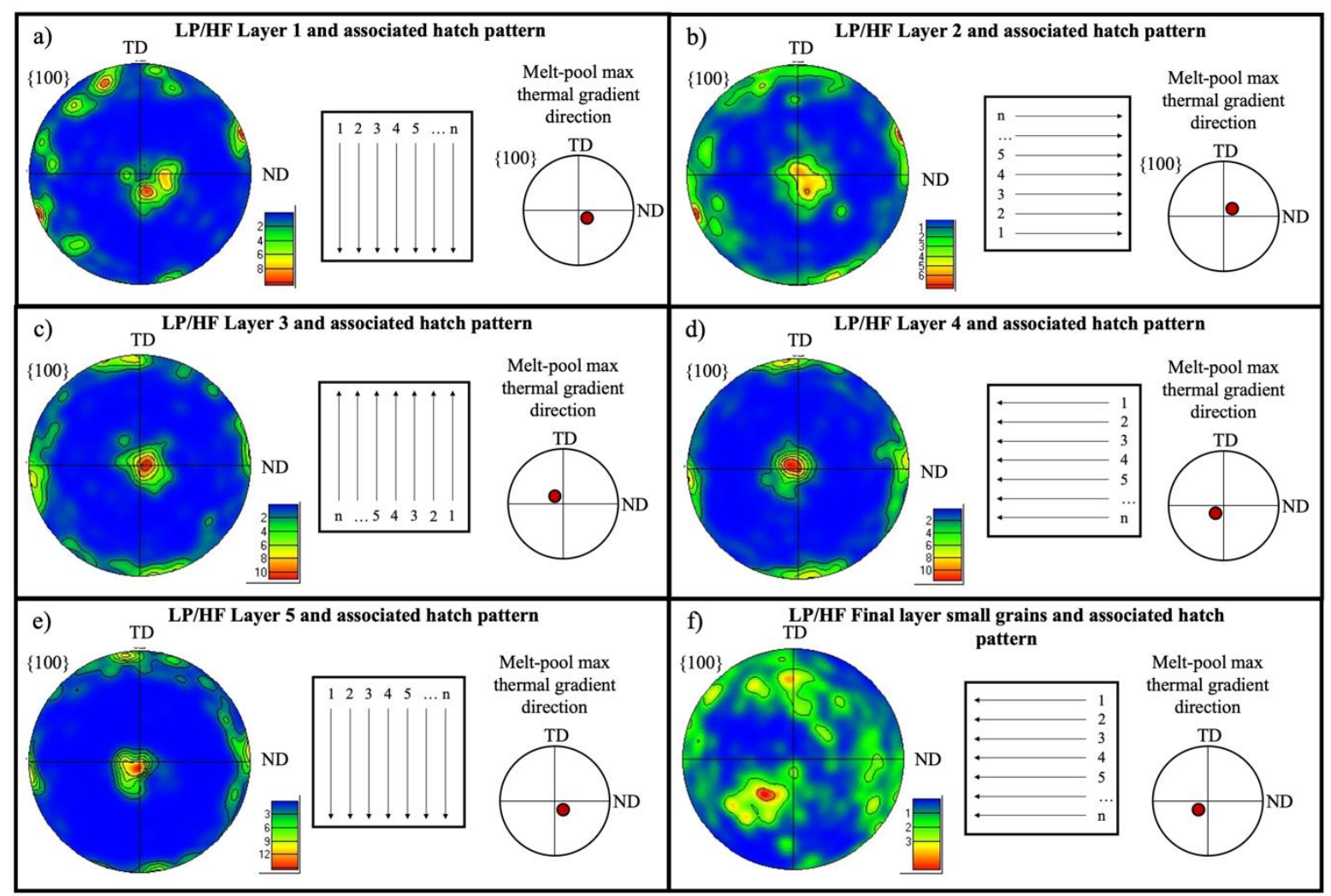

Figure 8 - (a-e): $\{100\}$ Pole figures for the first five layers and the associated hatch pattern for specimen LP/HF. (f): Pole figure for the equiaxed grains adjacent to top surface in the final layer of specimen LP/HF. Also included are pole figure representations of the predicted direction of maximum thermal gradient for each layer.

The global texture of specimens LP/MF and HP/MF is shown in Figure 9a and b. Specimen LP/MF displays a cube texture, and specimen HP/MF displays a $<001>/ / \mathrm{BD}$ fibre texture. It should be noted that specimen LP/MF and specimen LP/HF share similar texturing (cube), as does specimen HP/LF and HP/MF ( $<001>/ /$ BD fibre). The observed $<001>/ /$ fibre texture has been noted by many authors for AM Titanium material including Electron Beam Melted (EBM) Ti-6-4 [12,13], Construction Laser Additive Direct (CLAD) Ti-6-4 [27], and Laser Additively Manufactured (LAM) TC21 [28]. As previously discussed, the texture within any given layer is largely determined by the epitaxial growth of grains from the previous layer due to the large re-melting depths that remelt a significant portion of the heterogeneously nucleated grains at the top of the previous layer. Due to rotation of the scanning pattern by $90^{\circ}$ with each layer, any favourably oriented grain for layer $n$ will be unfavourably oriented for layer $n+1, n+2$ and $n+3$. Over many layers, the most favourably oriented grains will therefore have their $<001>$ pole aligned with $\mathrm{BD}$, leading to the prevalence of these grains and the observed global fibre texture.
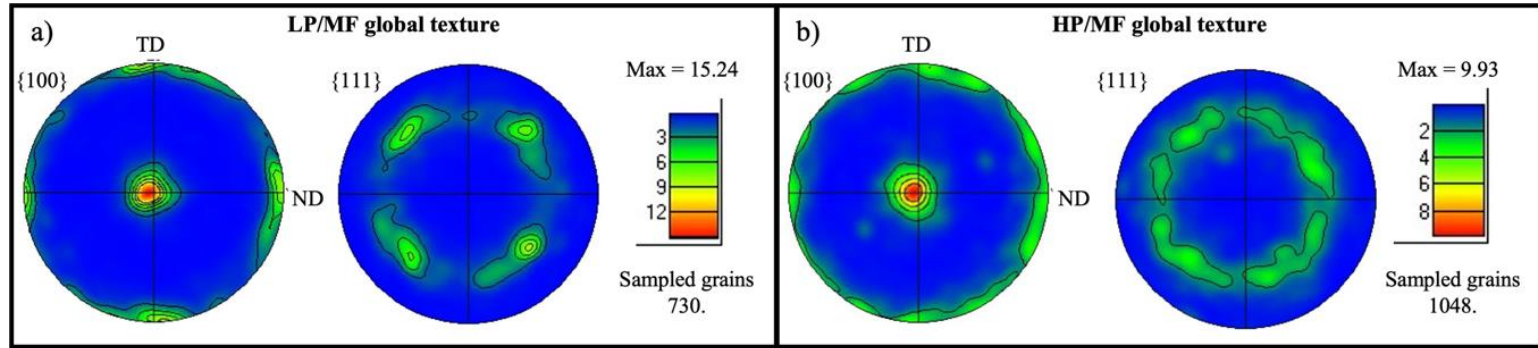

Figure 9 - Pole figures of the global texture of (a): specimen LP/MF, and (b): specimen HP/MF.

Cube texture components were identified within the material of specimens created with the low laser power of $550 \mathrm{~W}$ (Figure 9a). A similar texture has been observed for EBM Ti-6-4 by Antonysamy et al. and Al-Bermani et al. [12,29]. This has been hypothesised to be due to the elongated shape of the melt-pool; grains oriented with their remaining <001> poles aligned with the laser beam scanning directions will be able to grow faster laterally [12]. Over many layers, these grains become increasingly dominant, and hence produce the observed cube components in the texture. 
Difference in texture exists between specimen LP/MF and HP/MF as a result of laser power. The reason for this is not fully understood, but speculations can be made regarding differences in thermal gradients. In specimens created with higher laser powers, greater residual heat is likely to develop within the previous deposited layers and substrate. Increased residual heat would likely reduce thermal gradients in the melt-pool and increase the constitutional supercooling during solidification. Under these conditions greater $\beta$ grain growth of less favourable orientations can occur. This is reflected in the OIM maps of Figure 4 in which comparatively larger grains with a blue or green contrast can be seen in specimens created with a high laser power when the powder feed rate remains constant.

A significant proportion of the deposited microstructure is re-melted upon the deposition of subsequent layers, but features of the original bead microstructure are still visible as per comparison of Figure $6 \mathrm{~b}$ and $\mathrm{c}$. Based on this, a hypothesis on the microstructure development after multiple deposited tracks and layers have been produced Figure 10. Within each deposited track epitaxial growth occurs through the bottom of the melt-pool, and heterogeneous nucleation occurs towards the top and centre of the melt-pool. The heterogeneously nucleated grains will display a marginal tilt in their fibre texture away from BD and into the direction of maximum thermal gradient, but the majority of these grains are re-melted during subsequent deposition of tracks and layers. The probability of these fine grains being retained in the microstructure is therefore dependant on the re-melting depth of each track, and the size of the heterogeneous nucleated grains region. This morphology of columnar grains interspaced by equiaxed bands, sometimes called a 'bamboo' like microstructure, has been noted in other AM Tialloys $[11,21,24]$. Retention of these bands reduces the columnar $\beta$ grain size by 'breaking up' the columnar grains that would otherwise continue to grow epitaxially through many layers. The lack of presence of these bands in specimen LP/LF is demonstrated by columnar growth extending almost the entire build height.
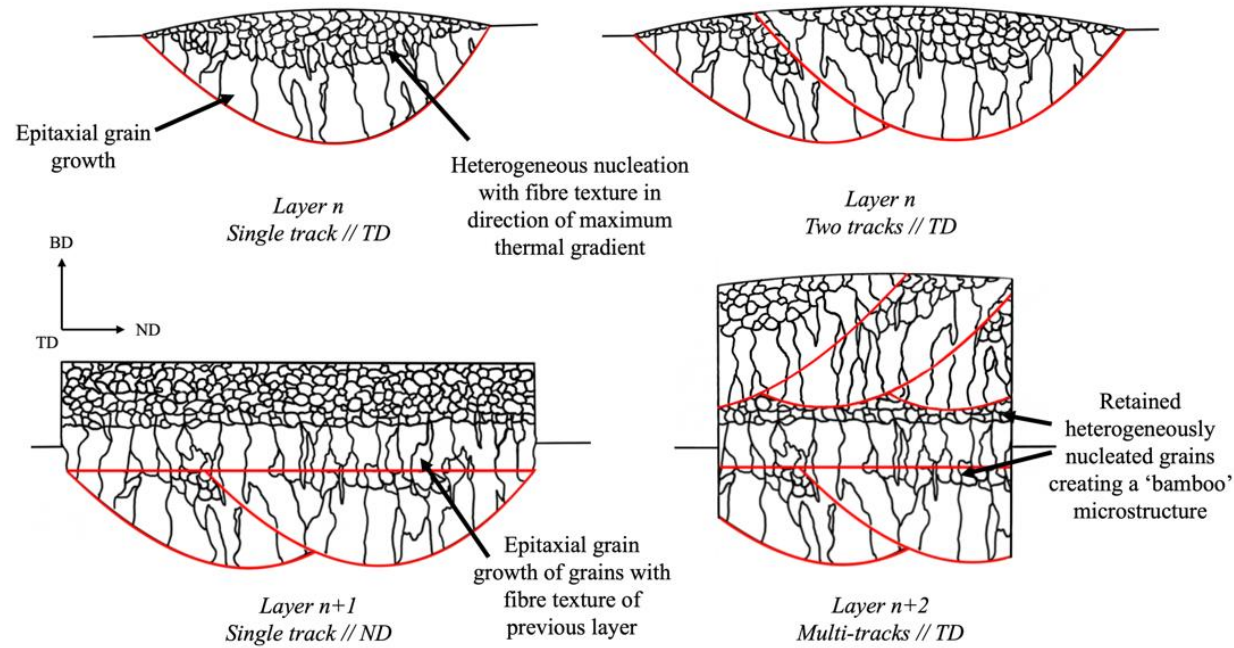

Figure 10 - Schematic explanation of the formation of assembly of small equiaxed grains retained in the microstructure after the deposition of subsequent layers.

\subsection{Microhardness and microstructure}

Microhardness distributions for each specimen through the build direction are shown in Figure 11. Unaffected substrate hardness values were $310 \mathrm{HV}$. The microhardness within the HAZ and FZ noticeably differed between each specimen; specimen HP/LF displayed a microhardness up to $390 \mathrm{HV}$, whilst LP/LF and LP/MF only peaked around $340 \mathrm{HV}$ and $315 \mathrm{HV}$ respectively. No spike in microhardness was noted within the HAZ of specimen LP/HF. Similar values were recorded within the lower layers of the builds, but by $4 \mathrm{~mm}$ beyond the substrate interface each specimen displayed microhardness values around $300 \mathrm{HV}$. The presence of such large microhardness variations is synonymous with non-uniform precipitation of a secondary phase such as the $\alpha$-phase, martensitic $\alpha$ " phase, or the meta-stable $\omega$ phase [30-32]. To this end, higher magnification SEM imaging has been implemented to characterize any secondary phase presence. 


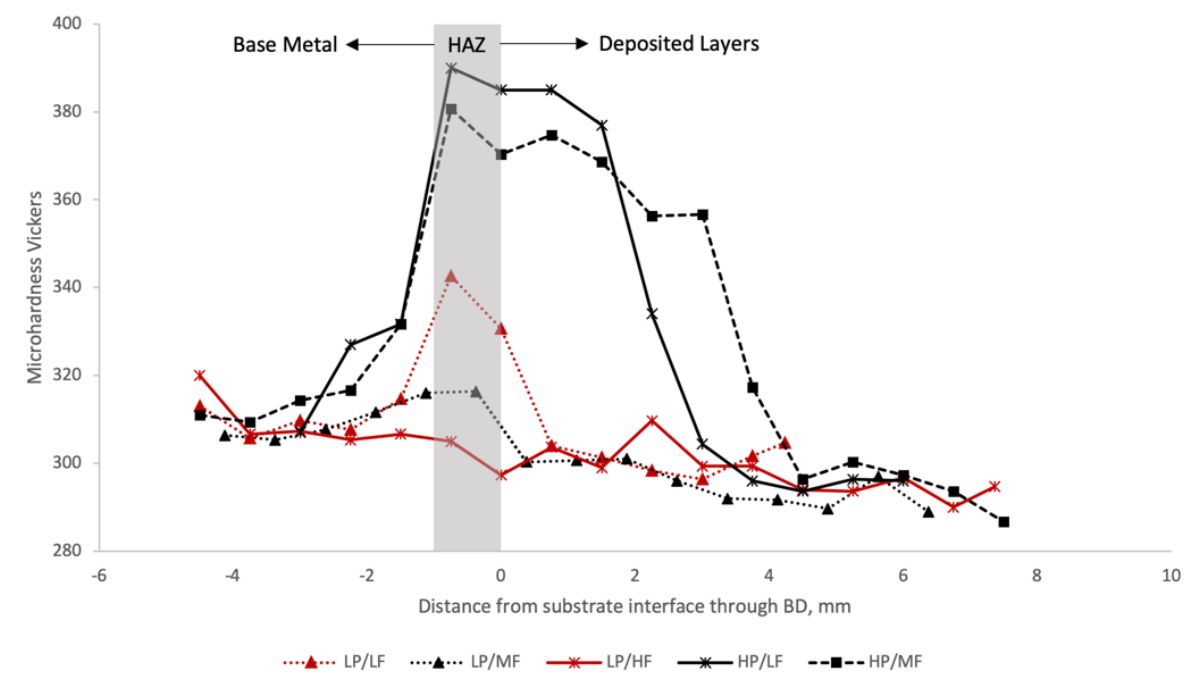

Figure 11 - Microhardness plots through the build direction.

Figure 12a shows a micrograph of specimen LP/MF unaffected substrate which is characterized by a homogeneous dispersion of micro-scaled $\alpha$ laths in the grain interiors and continuous grain boundary $\alpha(\mathrm{GB} \alpha)$ along $\beta$ grain boundaries. Within the HAZ, as shown in Figure 12b, the dissolution of the micro-scaled $\alpha$ laths into the $\beta$ matrix is visible. A progressive dissolution of $\alpha$ laths was observed nearing the FZ. Within the deposited material, the secondary phase morphology varied through the build height and from specimen to specimen forming along grain boundaries and interiors as acicular laths. It is therefore unlikely to be $\omega$ phase, which is not normally visible with SEM imaging, or $\alpha$ " phase, which does not typically form without additional stresses approaching the yield stress of Ti-5553 [33]. It is therefore a reasonable estimation that the phase is $\alpha$ phase, which has been noted in similar morphology in AM Ti-5553 [4,17,34].

Figure 13 shows high magnification SEM micrographs within the cross-sectioned centre of specimens created with a low and high laser power at various locations along BD. At the substrate interface, $\alpha$ was present along grain boundaries in all specimen. $1 \mathrm{~mm}$ above the substrate interface, no $\alpha$ was visible in specimen LP/MF (Figure 13b); however, in specimen HP/MF nano-scaled $\alpha$ precipitates were visible along grain boundaries in a discontinuous manner and homogeneously distributed in the grain interiors (Figure 13e). At $4 \mathrm{~mm}$ above the substrate interface $\alpha$ is still visible lining the grain boundary of specimen HP/MF, but there is no visible presence of $\alpha$ within the grain interiors (Figure 13). 

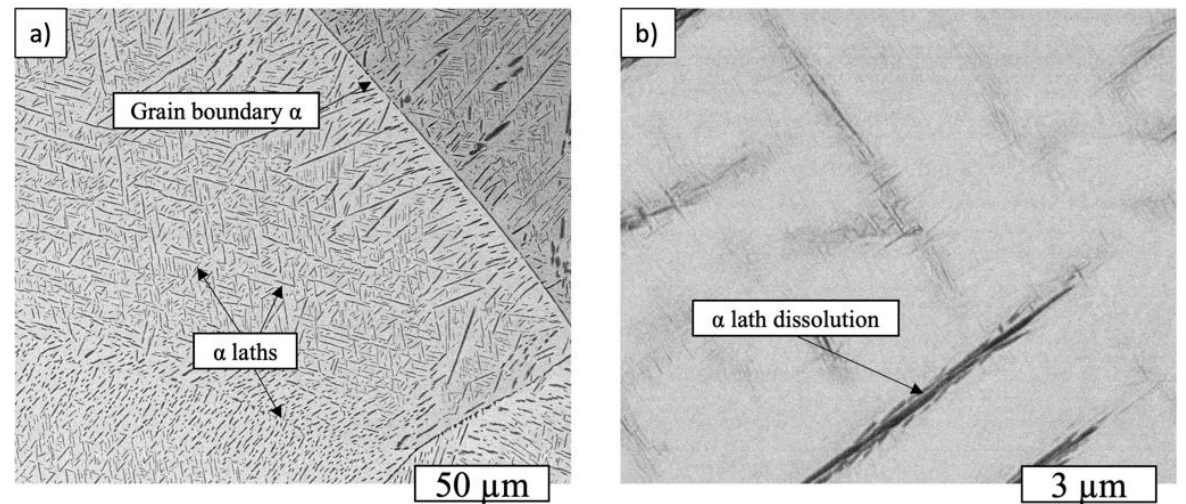

Figure 12 - Microstructure of the substrate (a), and HAZ (b) of specimen LP/MF.

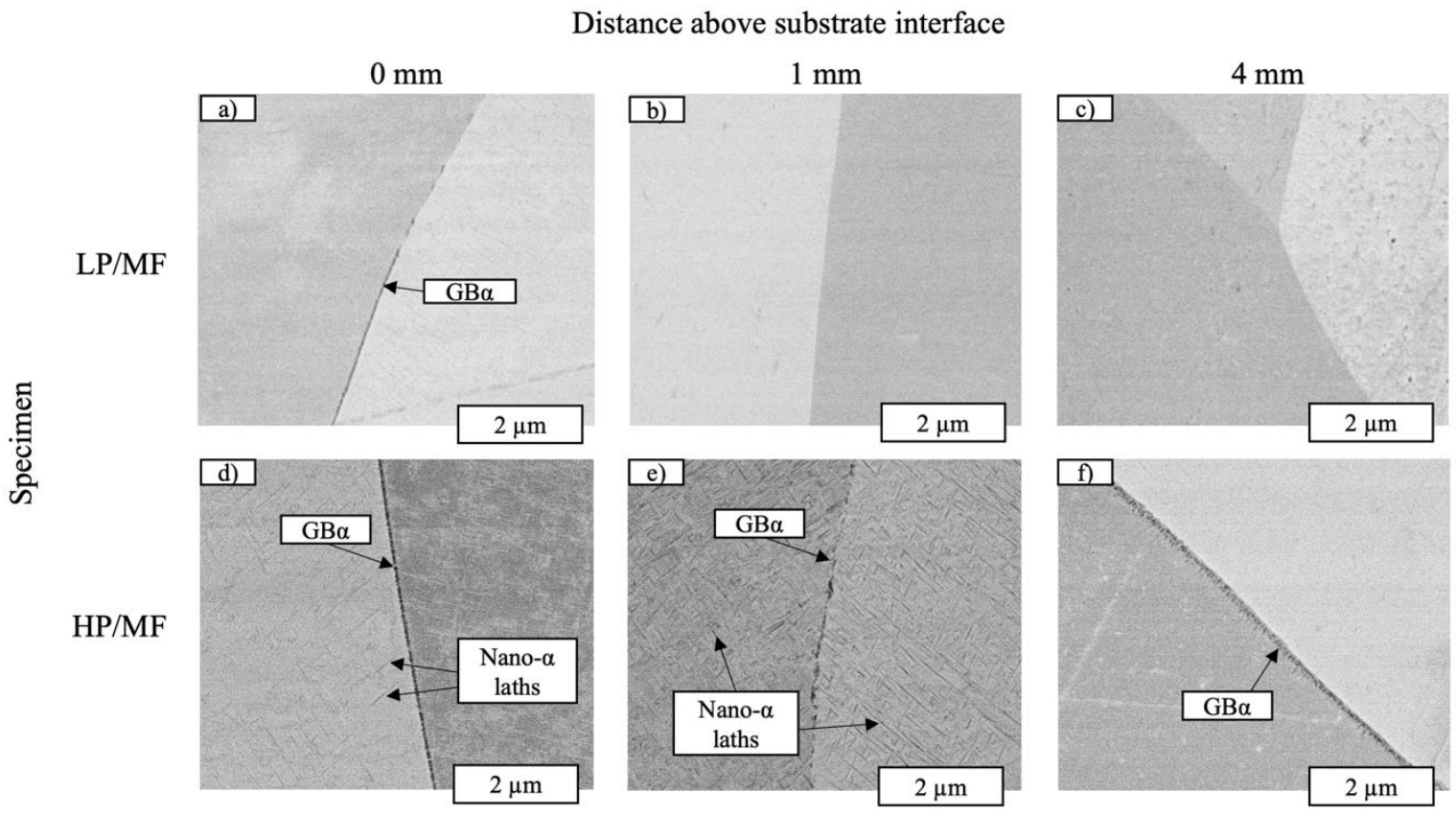

Figure 13 - Microstructure of various specimens: LP/MF (a-c) and HP/MF (d-f) at various locations through the build direction.

Unlike the widely used Ti-6-4 alloy, a characteristic feature of $\beta$-alloys, such as Ti-5553, is that no $\alpha$-phase is precipitated upon quenching from above the $\beta$-transus due to the sluggish precipitation kinetics of the $\alpha$-phase [14]. The rapid cooling inherent with LMD, which can be up to $10^{4} \mathrm{~K} / \mathrm{s}$ [35], should therefore precipitate no $\alpha$ upon deposition. However, as discussed, nano-scaled $\alpha$ precipitates were present in each specimen. The specimen created with the higher laser power displayed greater visible amounts of nano-scaled $\alpha$ precipitates under SEM and was more prominent within the lower layers compared to the upper layers of the build. Precipitation of $\alpha$ likely occurred through heat fluxes from the deposition of subsequent layers into the substrate and built-up residual heat within the build. This explains why the precipitation was only visible within the lower layers of the build, and that greater amounts were present within specimens created with the highest laser power i.e. at higher temperatures. Comparing Figure 11 and Figure 13, it can be seen that areas of increased microhardness correspond to areas of greater nano-scaled $\alpha$ precipitates. The dense nano-scaled $\alpha$ precipitates are known to dramatically increase the strength of meta-stable $\beta$-titanium alloys by increasing the number of dislocation barriers and is typically exploited through ageing treatments around $400-600^{\circ} \mathrm{C}$. Panza-Giosa demonstrated that microhardness in Ti-5553 increases rapidly during the first 20 minutes of ageing [36] which is approximately the same elapsed time during deposition of specimens within this work. It is therefore likely that builds developed with the high laser power of $650 \mathrm{~W}$ established a sufficiently large residual build temperature for long enough to allow an ageing-like response. 


\subsection{Dendrite morphology}

As previously mentioned in section 3.1, dendrites were visible in deposited layers of all specimens and are an indication of the solute segregation that occurs due to an unstable solidification front [37]. They extend through almost the entire layer height and are $\approx 5 \mu \mathrm{m}$ wide. Composition analyses of dendrites and inter-dendritic regions are shown in Figure 14(a-b). The analysis confirms a migration of solute elements, with the dendrite cores enriched with titanium, vanadium and chromium; whilst the inter-dendritic regions are enriched with molybdenum. This phenomenon has also been identified in EBM Ti-5553 [18] and LMD of Ti-55511 [11]. These micro-segregations mean the dendrite cores have $[\mathrm{Mo}]_{\mathrm{eq}}$ of solutes at up to $9.88 \%$ in comparison to the interdendritic regions which have a minimum of $9.14 \%$. Therefore, the dendritic cores are a more preferable location for $\alpha$ phase. Figure $14 \mathrm{c}$ and $\mathrm{d}$ show the microstructure within adjacent inter-dendritic and dendrite core regions of specimen HP/LF respectively. As predicted, a higher density of $\alpha$ laths are present within the core. Homogenisation heat treatments should be sought in order to reduce preferential $\alpha$ nucleation along these dendrite cores.

a)

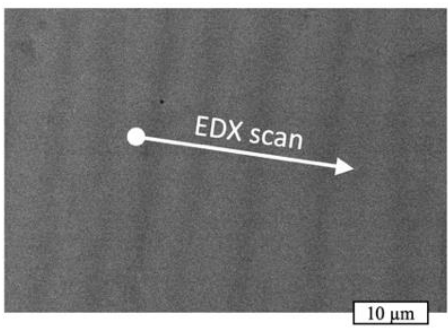

b)
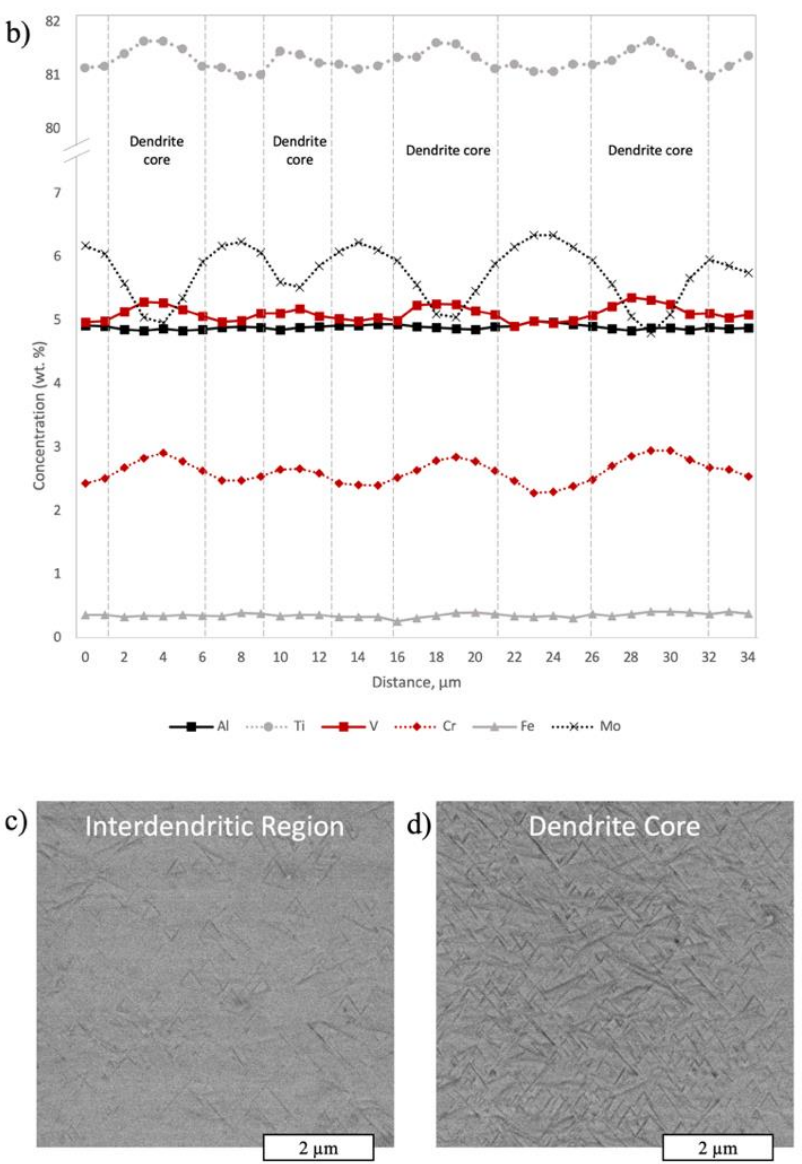

Figure 14 - (a) Location of EDX scan line, (b) chemical composition, (c-d) micrographs of $\alpha$ morphology in specimen HP/LF. 


\section{Conclusions}

Ti-5553 has been Laser Metal Deposited on Ti-5553 extracted from a forged billet under varying laser powers and powder feed rates for understanding of their effect on material behaviour:

- The as-deposited microstructure is characterised by large epitaxially grown $\beta$ grains up to several millimetres in length aligned in the building direction and clusters of fine equiaxed $\beta$ grains of $<120 \mu \mathrm{m}$ dispersed throughout the microstructure. Average $\beta$ grain size was smaller for specimens deposited with the highest powder feed rate of $2.3 \mathrm{~g} / \mathrm{min}$ compared to specimens deposited with $1.4 \mathrm{or} 1.8 \mathrm{~g} / \mathrm{min}$.

- Increase in powder feed rate or laser power increased the area fraction of grains less than $<120 \mu \mathrm{m}$ and the prominence of a 'bamboo' like microstructure of columnar grains interspersed by bands and clusters of heterogeneously nucleated grains.

- The texture of the heterogeneously nucleated grains is a $\langle 001\rangle$ fibre texture tilted away from the BD axis in the direction of maximum thermal gradient. The large re-melting penetration during LMD results in minimal heterogeneously nucleated grains within each layer remaining and a microstructure and texture dominated by epitaxially grown grains.

- $\quad$ Specimens created with a low laser power of $550 \mathrm{~W}$ displayed a cube texture, whilst specimens created with a higher laser power of $650 \mathrm{~W}$ displayed a $<001>/ / \mathrm{BD}$ fibre texture.

- Areas of high microhardness of up to $390 \mathrm{HV}$ have been noted in the HAZ and lower deposited layers of specimens deposited with the higher laser power of $650 \mathrm{~W}$ and have been interrelated with areas of increased nano-scaled $\alpha$ precipitates.

- Micro-segregation of solutes during the rapid solidification of the melt-pool produced dendritic regions locally higher in $\alpha$-stabilisers which were preferential locations for $\alpha$ precipitates.

\section{Acknowledgements}

The authors would like to acknowledge the support provided by the Advanced Forming Research Centre (AFRC), University of Strathclyde, which receives partial financial support from the UK's High Value Manufacturing CATAPULT.

\section{Data availability}

The raw/processed data required to reproduce these findings cannot be shared at this time as the data also forms part of an ongoing study.

\section{References}

[1] B. Dutta, F.H. (Sam) Froes, The Additive Manufacturing (AM) of titanium alloys, Met. Powder Rep. 72 (2017) 96-106. doi:10.1016/j.mprp.2016.12.062.

[2] S. Ford, M. Despeisse, Additive manufacturing and sustainability: an exploratory study of the advantages and challenges, J. Clean. Prod. 137 (2016) 1573-1587. doi:10.1016/j.jclepro.2016.04.150.

[3] D.D. Gu, W. Meiners, K. Wissenbach, R. Poprawe, Laser additive manufacturing of metallic components: materials, processes and mechanisms, Int. Mater. Rev. 57 (2012) 133-164. doi:10.1179/1743280411Y.0000000014.

[4] A. Hatefi, Direct Laser Fabrication of Ti-5553, University of Birmingham, 2013. http://etheses.bham.ac.uk/4667/2/Hatefi13MRes.pdf (accessed November 9, 2017).

[5] V. Chastand, A. Tezenas, Y. Cadoret, P. Quaegebeur, W. Maia, E. Charkaluk, Fatigue characterization of Titanium Ti-6Al-4V samples produced by Additive Manufacturing, Procedia Struct. Integr. 2 (2016) 3168-3176. doi:10.1016/j.prostr.2016.06.395.

[6] M. Seifi, A. Salem, D. Satko, J. Shaffer, J.J. Lewandowski, Defect distribution and microstructure heterogeneity effects on fracture resistance and fatigue behavior of EBM Ti-6Al-4V, Int. J. Fatigue. 94 (2017) 263-287. doi:10.1016/j.ijfatigue.2016.06.001.

[7] M.N. Ahsan, A.J. Pinkerton, R.J. Moat, J. Shackleton, A comparative study of laser direct metal deposition characteristics using gas and plasma-atomized Ti-6Al-4V powders, Mater. Sci. Eng. A. 528 (2011) 7648-7657. doi:10.1016/j.msea.2011.06.074.

[8] M. Strantza, B. Vrancken, M.B. Prime, C. Truman, M. Rombouts, D.W. Brown, P. Guillaume, D. Van Hemelrijck, Directional and oscillating residual stress on the mesoscale in additively manufactured Ti6Al-4V, Acta Mater. (2019). doi:10.1016/J.ACTAMAT.2019.01.050.

[9] B.A. Szost, S. Terzi, F. Martina, D. Boisselier, A. Prytuliak, T. Pirling, M. Hofmann, D.J. Jarvis, A 
comparative study of additive manufacturing techniques: Residual stress and microstructural analysis of CLAD and WAAM printed Ti-6Al-4V components, Mater. Des. 89 (2016) 559-567. doi:10.1016/j.matdes.2015.09.115.

[10] J. Zhang, X. Wang, S. Paddea, X. Zhang, Fatigue crack propagation behaviour in wire+arc additive manufactured Ti-6Al-4V: Effects of microstructure and residual stress, (2016). doi:10.1016/j.matdes.2015.10.141.

[11] C.M. Liu, X.J. Tian, H.B. Tang, H.M. Wang, Microstructural characterization of laser melting deposited Ti-5Al-5Mo-5V-1Cr-1Fe near $\beta$ titanium alloy, J. Alloys Compd. 572 (2013) 17-24. doi:10.1016/j.jallcom.2013.03.243.

[12] A.A. Antonysamy, J. Meyer, P.B. Prangnell, Effect of build geometry on the $\beta$-grain structure and texture in additive manufacture of Ti6Al4V by selective electron beam melting, Mater. Charact. 84 (2013) 153168. doi:10.1016/j.matchar.2013.07.012.

[13] C. de Formanoir, S. Michotte, O. Rigo, L. Germain, S. Godet, Electron beam melted Ti-6Al-4V: Microstructure, texture and mechanical behavior of the as-built and heat-treated material, Mater. Sci. Eng. A. 652 (2016) 105-119. doi:10.1016/j.msea.2015.11.052.

[14] G. Lütjering, J.C. Williams, Titanium, Ed. SPRINGER. second edi (2007) 1-442. doi:10.1007/978-3540-73036-1.

[15] Y.Y. Zhu, H.B. Tang, Z. Li, C. Xu, B. He, Solidification behavior and grain morphology of laser additive manufacturing titanium alloys, J. Alloys Compd. 777 (2019) 712-716. doi:10.1016/j.jallcom.2018.11.055.

[16] M.J. Bermingham, S.D. McDonald, D.H. StJohn, M.S. Dargusch, Beryllium as a grain refiner in titanium alloys, J. Alloys Compd. 481 (2009) 20-23. doi:10.1016/j.jallcom.2009.03.016.

[17] C. Qiu, G.A. Ravi, M.M. Attallah, Microstructural control during direct laser deposition of a $\beta$-titanium alloy, Mater. Des. 81 (2015) 21-30. doi:10.1016/j.matdes.2015.05.031.

[18] J.C. Sabol, Analysis of Microstructural Evolution and Fracture Mechanisms in Ti-5Al-5V-5Mo-3Cr0.4Fe in Response to Electron Beam Welding and Post Weld Heat Treatments, (2014) 153.

[19] Q. Zhang, J. Chen, L. Wang, H. Tan, X. Lin, W. Huang, Solidification Microstructure of Laser Additive Manufactured Ti-6Al-2Zr-2Sn-3Mo-1.5Cr-2Nb Titanium Alloy, J. Mater. Sci. Technol. 32 (2016) 381386. doi:10.1016/j.jmst.2015.11.019.

[20] Y. Zhu, X. Tian, J. Li, H. Wang, Microstructure evolution and layer bands of laser melting deposition Ti6.5 Al-3.5Mo-1.5Zr-0.3Si titanium alloy, J. Alloys Compd. 616 (2014) 468-474. doi:10.1016/j.jallcom.2014.07.161.

[21] T. Wang, Y.Y. Zhu, S.Q. Zhang, H.B. Tang, H.M. Wang, Grain morphology evolution behavior of titanium alloy components during laser melting deposition additive manufacturing, J. Alloys Compd. 632 (2015) 505-513. doi:10.1016/j.jallcom.2015.01.256.

[22] B. He, J. Li, X. Cheng, H.M. Wang, Brittle fracture behavior of a laser additive manufactured near- $\beta$ titanium alloy after low temperature aging, Mater. Sci. Eng. A. 699 (2017) 229-238. doi:10.1016/j.msea.2017.05.050.

[23] T. DebRoy, H.L. Wei, J.S. Zuback, T. Mukherjee, J.W. Elmer, J.O. Milewski, A.M. Beese, A. WilsonHeid, A. De, W. Zhang, Additive manufacturing of metallic components - Process, structure and properties, Prog. Mater. Sci. 92 (2018) 112-224. doi:10.1016/j.pmatsci.2017.10.001.

[24] C.M. Liu, H.M. Wang, X.J. Tian, H.B. Tang, D. Liu, Microstructure and tensile properties of laser melting deposited Ti-5Al-5Mo-5V-1Cr-1Fe near $\beta$ titanium alloy, Mater. Sci. Eng. A. 586 (2013) 323-329. doi:10.1016/j.msea.2013.08.032.

[25] J.A. Spittle, Columnar to equiaxed grain transition in as solidified alloys, Int. Mater. Rev. 51 (2006) $247-$ 269. doi:10.1179/174328006X102493.

[26] S. Suwas, R.K. Ray, Crystallographic Texture of Materials, Springer, 2014.

[27] C. Schneider-Maunoury, L. Weiss, P. Acquier, D. Boisselier, P. Laheurte, Functionally graded Ti6Al4VMo alloy manufactured with DED-CLAD ${ }^{\circledR}$ process, Addit. Manuf. 17 (2017) 55-66. doi:10.1016/j.addma.2017.07.008.

[28] Q. Zhang, J. Chen, P. Guo, H. Tan, X. Lin, W. Huang, Texture and microstructure characterization in laser additive manufactured Ti-6Al-2Zr-2Sn-3Mo-1.5Cr-2Nb titanium alloy, Mater. Des. 88 (2015) 550557. doi:10.1016/j.matdes.2015.09.053.

[29] S.S. Al-Bermani, M.L. Blackmore, W. Zhang, I. Todd, The origin of microstructural diversity, texture, and mechanical properties in electron beam melted Ti-6Al-4V, Metall. Mater. Trans. A Phys. Metall. Mater. Sci. 41 (2010) 3422-3434. doi:10.1007/s11661-010-0397-x.

[30] A. Dehghan-Manshadi, R.J. Dippenaar, Development of alpha-phase morphologies during low temperature isothermal heat treatment of a Ti-5Al-5Mo-5V-3Cr alloy, Mater. Sci. Eng. A. 528 (2010) 1833-1839. doi:10.1016/j.msea.2010.09.061.

[31] X. Ma, F. Li, Z. Sun, J. Hou, X. Fang, Y. Zhu, C.C. Koch, Achieving Gradient Martensite Structure and 
Enhanced Mechanical Properties in a Metastable $\beta$ Titanium Alloy, Metall. Mater. Trans. A Phys. Metall. Mater. Sci. 50 (2019) 2126-2138. doi:10.1007/s11661-019-05157-5.

[32] Y. Yao, X. Li, Y.Y. Wang, W. Zhao, G. Li, R.P. Liu, Microstructural evolution and mechanical properties of Ti-Zr beta titanium alloy after laser surface remelting, J. Alloys Compd. 583 (2014) 43-47. doi:10.1016/j.jallcom.2013.08.160.

[33] P. Barriobero-Vila, J. Gussone, K. Kelm, J. Haubrich, A. Stark, N. Schell, G. Requena, An in situ investigation of the deformation mechanisms in a $\beta$-quenched Ti-5Al-5V-5Mo-3Cr alloy, Mater. Sci. Eng. A. 717 (2018) 134-143. doi:10.1016/j.msea.2018.01.077.

[34] H. Schwab, M. Bönisch, L. Giebeler, T. Gustmann, J. Eckert, U. Kühn, Processing of Ti-5553 with improved mechanical properties via an in-situ heat treatment combining selective laser melting and substrate plate heating, (2017). doi:10.1016/j.matdes.2017.05.010.

[35] B. Zheng, Y. Zhou, J.E. Smugeresky, J.M. Schoenung, E.J. Lavernia, Thermal behavior and microstructural evolution during laser deposition with laser-engineered net shaping: Part I. Numerical calculations, Metall. Mater. Trans. A Phys. Metall. Mater. Sci. 39 (2008) 2228-2236. doi:10.1007/s11661-008-9557-7.

[36] R. Panza-Gios, The Effect of Heat Treatment on the Microstructure Evolution and Mechanical Properties of Ti-5Al-5V-5Mo-3Cr, and Its Potential Application in Landing Gears., McMaster University, 2009.

[37] A.L. Anis, M.K. Talari, N. Kishore Babu, M.H. Ismail, G.D. Janaki Ram, I.A. Mohd Arif, Grain refinement of Ti-15V-3Cr-3Sn-3Al metastable $\beta$ titanium alloy welds using boron-modified fillers, $\mathrm{J}$. Alloys Compd. 749 (2018) 320-328. doi:10.1016/j.jallcom.2018.03.286. 